\title{
The next step in sustainable dining: the restaurant food waste map for the management of food waste
}

\section{Ludovica Principato, et al. [full author details at the end of the article]}

Received: 30 June 2020 / Accepted: 1 June 2021 / Published online: 18 July 2021

(c) Società Italiana Marketing 2021

\begin{abstract}
In recent years, out-of-home food waste is growing exponentially and therefore represents an important focus of attention, albeit little research has been done on this instance. A few researchers have developed frameworks to better explain wasteful behaviors away from home, however a comprehensive interpretation of the phenomenon giving indications for maps/guidelines for the foodservice managers has not been carried out. In this paper, as a result of a thematic literature review, the Restaurant Food Waste Map (RFWM) was designed to describe the phases in which the food waste phenomenon occurs, and to identify mitigation activities of food waste generation processes. The proposed map is aimed to describe three phases in which the food waste phenomenon occurs: (1) kitchen food preparation, (2) food service, and (3) clients' consumption. Moreover, the present map highlights the approaches that restaurants could take into consideration to better manage the food waste: (1) prevention, (2) reduction, and (3) reuse/redistribution of food waste. These approaches set out guidance on the preferred methods of dealing with food waste so as to minimize its impact on the environment and society. The present study provides literature knowledge about food waste management at the restaurant level, and highlights some practical implications. Further studies could explore and analyze out-of-home waste from both the client and business perspective according to the proposed RFWM, to target specific attitudes and behavioral changes, and to quantify the impacts of the suggested changes. Reducing food waste is a key sustainability challenge for the food service industry. Despite the significance of this issue, a comprehensive interpretation of the phenomenon giving indications for maps/ guidelines for the foodservice managers has received limited attention in the literature. As a result of a thematic literature review, the RFWM was designed to describe the phases in which the food waste phenomenon occurs, and to identify mitigation activities of food waste generation processes with practice-driven initiatives an organized map has been developed. The proposed map is aimed to describe three phases in which the food waste phenomenon occurs: (1) kitchen food preparation, (2) food service, and (3) clients' consumption. Moreover, the present map highlights the approaches that restaurants could take into consideration to reduce food waste: (1) prevention, (2) reduction, and (3) reuse/redistribution of food waste. The present study provides literature knowledge about food waste management at the restaurant
\end{abstract}


level, and highlights some practical implications. Further studies could explore and analyze out-of-home waste from both the client and business perspective according to the proposed RFWM, to target specific attitudes and behavioral changes, and to quantify the impacts of the suggested changes. The concepts discussed here could help practitioners to become more aware of the factors that drive the adoption of food waste management practices.

Keywords Food waste - Wasteful behavior $\cdot$ Restaurant waste $\cdot$ Consumer waste $\cdot$ Restaurant management $\cdot$ Out-of-home waste

\section{Introduction}

How much food is wasted in the world? Food waste has reached a frightening dimension: one-third of the food produced in the world suffers this end (FAO 2019). The FAO gave the first definition of food waste in 1981 as "some wholesome edible material intended for human consumption, arising at any point in the food supply chain that is instead discarded, lost, degraded or consumed by pests". Fanfani (2009) defines "waste" as a product that has lost its commercial value and consequently tends to be considered a "commodity", but not its qualities and function as food. According to the author, it is possible to distinguish between products designed for disposal as waste (absolute waste), those that find an alternative processing route to food consumption (relative waste), and those that could be improved for the purpose for which they were originally shaped, even though they have lost their commercial value. In fact, food that the market is unable to allocate, or rather "surpluses" are defined as "surplus" and "unsold" in the transformation and distribution phases, due to situations such as irregular shapes in products, damage, expiry dates.

Food waste has considerable and varied social, environmental and economic ethics impacts (Eriksson et al. 2017; Principato et al. 2020, 2021; Vandermeersch et al. 2014). The literature is increasingly focusing on the identification and estimation of the impact of innovative strategies for the valorization of food waste (Arancon et al. 2013; Thyberg and Tonjes 2016; Venkat 2011), as well as on the identification of practical and sustainable solutions to be applied on a small and a global scale (Papargyropoulou et al. 2014). However, all actors in the food chain have a role to play in preventing and reducing waste: from those who produce and process foods (farmers, food manufacturers, and processors) to those who make foods available for consumption (hospitality sector, retailers), and ultimately consumers themselves. Recent studies of the European Community, conducted between 2014 and 2016, have shown that the main source of food waste in restaurants are the leftovers of customers: what makes the difference is what remains on the plate, which is not eaten at the table or taken home, and that restaurateurs are forced to throw away (Stenmarck et al. 2016). Reducing food waste has enormous potential to decrease the resources we use to produce the food we eat, and has a triple win: (1) it saves food for human consumption; (2) helps farmers, companies, and consumers to save money; and (3) lowers the environmental impact of food production and consumption. 
This paper is focused on activities that occur out-of-home, and specifically within the foodservice industry. It includes full-service providers (e.g. restaurants), cafés/ bars, take-away and delivery, fast food, self-service cafeterias (located in corporate or school environments), to kiosks and catering services (Euromonitor 2016) and food waste management practices have not only environmental and social sustainability, but also economic implications. A recent report found that for every $\$ 1$ restaurant invested in programs to reduce kitchen food waste, on average restaurants saved $\$ 7$ in operating costs (Champions 123 2019).

Because of the considerable importance of this issue, several studies have begun to examine the food waste phenomenon during the out-of-home phase by providing a conceptual framework for determining the actors and behaviors (Evans 2014; Filimonau and Delysia 2019; Papargyropoulou et al. 2014; Principato 2018; Quested et al. 2013). In particular, Principato (2018) in her conceptual framework of awayfrom-home waste provided a first attempt of the responsible actors and the correct behaviors that significantly tackle food waste during the out-of-home phase. However, this framework lacks a specific focus on food wasted during the service phase, and, most importantly, it does not highlight management strategies to reduce the phenomenon strategically and consistently.

Indeed, while there is good evidence about food waste quantification in food service (for example Betz et al. 2015; Papargyropoulou et al. 2016; Pirani and Arafat 2016), up to now the literature provides few studies on how foodservice professionals approach food waste management practices along with the entire foodservice, and map in an organized way which are the best practices to prevent, reduce and redistribute it under the EPA Food Recovery Hierarchy (FRH) (Heikkilä et al. 2016; Cicatiello et al. 2016). As shown in Fig. 1, FRH prioritizes food waste reduction strategies compared to redistribution or disposal (EPA 2019). Despite Food Waste

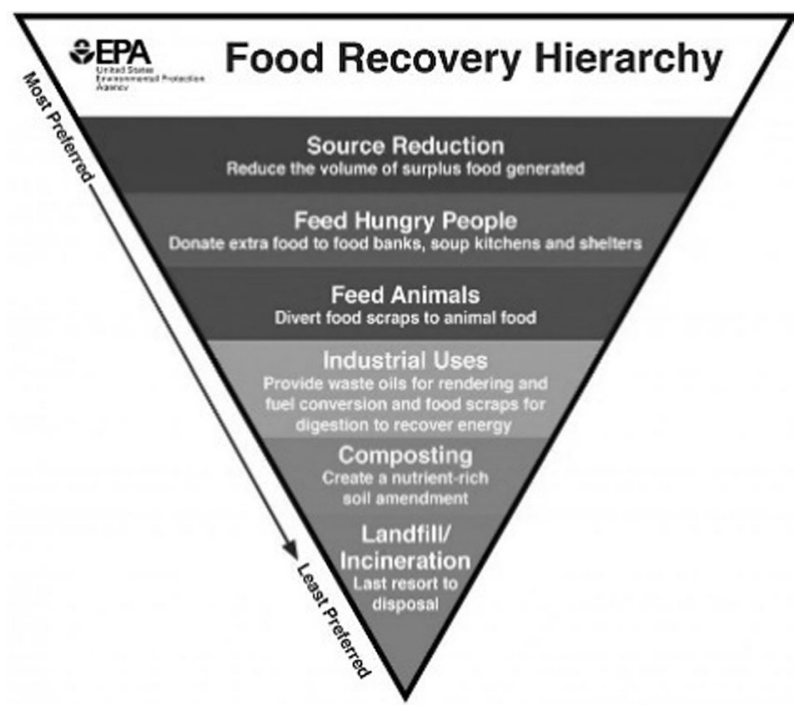

Fig. 1 Food recovery hierarchy model. Source: EPA (2019) 
Hierarchy sets out guidance on the preferred methods of dealing with food waste (e.g. Mourad 2016; Papargyropoulou et al. 2014), the activities and priorities of frontline workers and department managers are unknown. However, this framework constitutes a basis for defining the principal mitigation actions to be applied in food waste management.

In this paper we analyze and investigate the factors that support or impede wasteful performance, thus suggesting a map to better explaining restaurant food waste management for the food service industry, and at the same time provide strategies to prevent, reduce, and redistribute food waste.

The main research question that this study seeks to answer is:

Which are the approaches that restaurants should take into consideration to reduce food waste along with different phases of food waste generation?

To ensure that all food waste activities in restaurants could be properly outlined according to the most relevant thematic literature on this instance, we organized a map for the foodservice managers called "Restaurant Food Waste Map" (RFWM), streamlining various areas of the literature on food waste phenomena, and highlighting the main causes of restaurant food waste and the related actors. The theoretical context applied to describe food waste at the restaurant level was build based on the knowledge made by the most relevant studies on kitchen food waste, service food waste, and client food waste (Risku-Norja et al. 2010; Papargyropoulou et al. 2014; Marthinsen et al. 2012; Heikkila et al. 2016; Sustainable Restaurant Association 2010).

Firstly, we evaluated the key actors accountable for food waste (restaurant managers/chefs, staff, and restaurant clients); we then analyzed the activities and behaviors that can significantly reduce food waste at both restaurant and consumers level, how to reduce or recycle waste following specific procedures, and proposed a conceptual framework to enhance the relationships that emerged between the variables that lead to the creation of food waste and mitigation activities for each phase outlined. In the final section, we highlight the theoretical and managerial contributions of the study and get recommendations for future research paths. The support to the literature of this research is twofold: (1) it helps to better understand why and when food is wasted at the restaurant level; (2) it presents a theoretical framework that explains the restaurant food waste phenomenon focusing on a business perspective.

\section{The restaurant food waste map (FRWP)}

The following table (Table 1) introduces the RFWM map, that is aimed to describe three phases in which the food waste phenomenon occurs: (1) kitchen food preparation, (2) food service and staff activities, and (3) consumption by clients (RiskuNorja et al. 2010; Papargyropoulou et al. 2016; Betz et al. 2015; Marthinsen et al. 2012; Pirani and Arafat 2016; Heikkila et al. 2016; Sustainable Restaurant Association 2010).

The following paragraphs organize and describe in detail the major activities organized within the RFWM. 


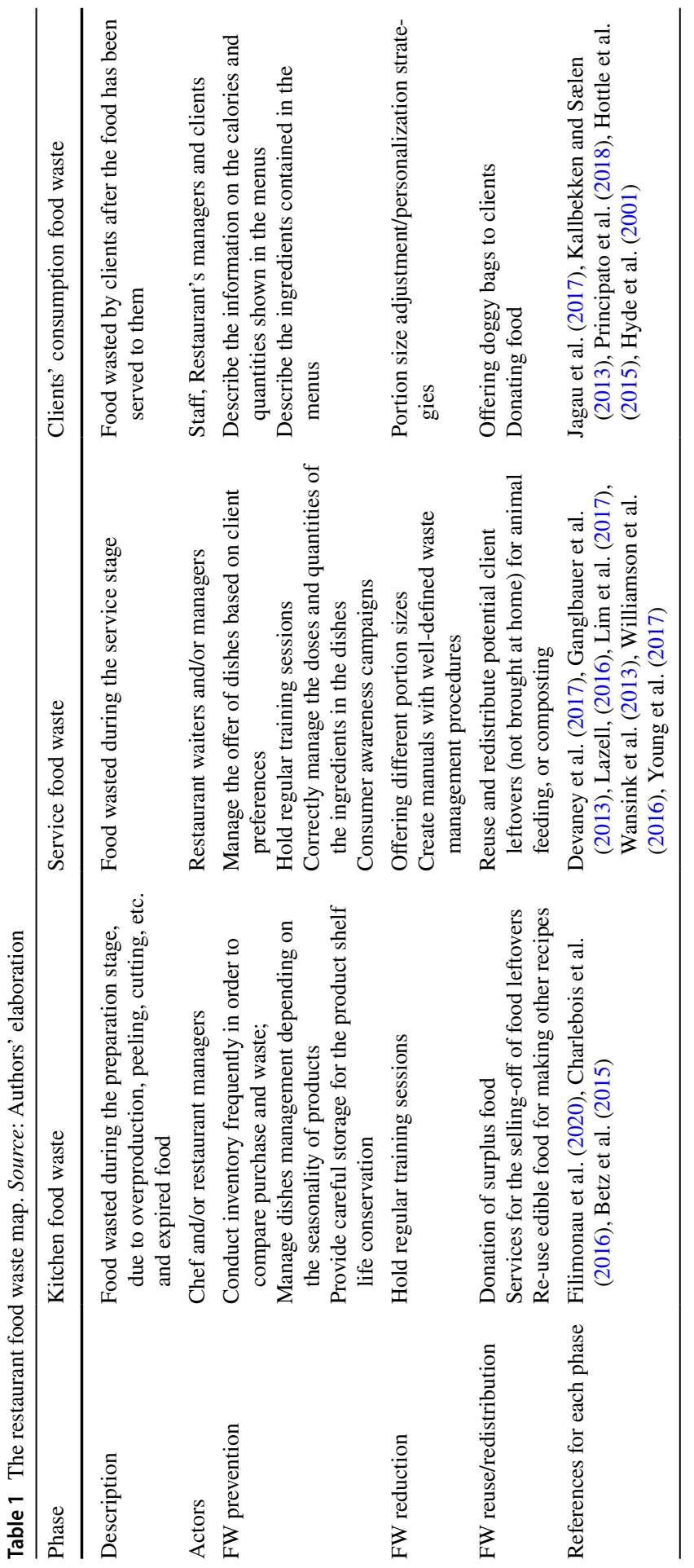




\subsection{Kitchen food waste (KFW)}

\subsubsection{Description}

KFW occurs during the preparation phase for reasons associated with "overproduction, peeling, cutting, expiration, spoilage, overcooking, etc." (Papargyropoulou et al. 2016, p. 4). Thus, the responsibilities linked to the phenomenon lays to the restaurant or catering manager or the chef for KFW. Moreover, our map not only considers the food waste reduction behaviors, which characterize the tip of the waste hierarchy (EPA 2013) but once the phenomenon happens, we should also consider which would be the best behaviors to reprocess it.

\subsubsection{Actors}

According to Martin-Rios and Demen-Meier (2018), food waste is mainly produced in kitchens and back-offices (trimmings and peelings, bones, packaging) or frontoffice operations. At that stage, the most important role in the generation and exploitation of wasted food is in the charge of chefs and restaurant managers for activities performed before the service phase and in the ingredient procurement phase, as well as in the proper storage of ingredients (WRAP 2015).

\subsubsection{Causes}

Pre-consumer waste offers opportunities for waste reduction and cost savings (LeanPath 2008; Martinez-Sanchez et al. 2016). This seems almost paradoxical since, in this era of globalization, restaurants are struggling to cut their costs. Restaurants can do a lot to minimize the potential cost increases by incorporating simple recycling and waste reduction programs and procedures or considering a better purchase, prepare and present foods considering seasonal use of foodstuffs (Gössling et al. 2011). Measurement is critical to food waste prevention, as it ensures a clear evidence base on which to build effective strategies (Collison and Colwill 1985). Tracking the choice of unpopular dishes might help chefs to consider adjusting the recipe or removing it from the menu (Martin-Rios and Demen-Meier 2018). In addition, the presence within the menu of a high number of dishes can lead to confusion in customers' choice of what to choose.

\subsubsection{Management strategies}

Chefs could create new alternative recipes from the leftover ingredients of offered dishes that remain in the preparation phase, respecting the hygiene standards. For example, soups, broths, gravies, and sauces can be made from leftovers, or ruined fruits and vegetables can be juiced for drinks and sauces. In addition, they may focus on pre-service preparation based on dish popularity, to minimize the use of products that may not be required during the service phase.

Restaurant managers are required to coordinate actions across all staff in the procurement of the products, considering also environmental criteria. it is also important 
to provide careful storage (e.g. correct adjustment of refrigeration temperature) for product shelf life conservation, and working off of accurate inventory management (Sustainable Restaurant Association 2010), ordering based on historical sales trends and waste records (WRAP 2015), and based on the seasonality of ingredient availability (Kreeger et al. 2018).

Food management improvements could focus on reducing waste by either introducing process and operational improvements, or introducing new technology, that requires a low or high degree of new knowledge (Ruiz-Molina et al. 2014). For example, the application of the Internet of Things technology for improving food waste management (in collection and transportation of food), requires sophisticated management systems and involves high-level technical skills.

Once food waste has been generated, for restaurants it can be necessary to understand how to reuse products holistically, usually with the support of third parties (Mourad 2016). For example, Biova Bread Beer is an Italian startup that works by stimulating the production of goods with zero environmental impact and educating consumers on their use. Biova defines itself as a movement, in which anyone can participate in multiple forms. Excess bread is recovered from or to bakeries; it is taken to the nearest brewery among those that join the movement; and it is returned, in the form of beer. Biova has adopted a logic of co-branding of the product that leads to a win-win relationship with its suppliers which become partners for distribution. In 2020, thanks to the project, a ton of bread were recovered, and for every $150 \mathrm{kilos}, 2500 \mathrm{~L}$ of Bread Beer are created, 1365 kilos of $\mathrm{CO}_{2}$ are saved (www.biovaproject.com).

\subsection{Service food waste (SFW)}

\subsubsection{Description}

Service food waste is defined as food discarded by staff within the control of the foodservice operator. It could also consist of waste related to the front of the counter, such as salad bars, steam wells, or miss-ordered products (i.e. waiter/waitress mistakenly noted).

Large producers of waste during the service phase are the buffets, which usually involve the preparation of a large amount of food compared to what is needed, as it is not always possible to reuse or donate most of the products that are put on the tables due to health and hygiene restrictions (Eriksson et al. 2017). Catering services generate a considerable daily cost that can lead to a loss of economic profitability as well as sustainable impact. One of the most important costs concerns food leftovers that are directly thrown away without considering the expense incurred for the purchase of raw materials and the realization of the finished product (Chou et al. 2012; Curtis et al. 2016).

\subsubsection{Actors}

At this stage, chefs, restaurant managers, waiters, and all staff need to be more aware of how they can change their habits to achieve waste reduction targets. This also 
includes encouraging clients to take part in the initiative by ordering dishes smartly and conscientiously and making clients aware of the amount of food thrown away from the meals served.

\subsubsection{Causes}

Key aspects that emerged from previous studies in working on food waste management during dining is the preparation of the staff through sustainability programmes. For example, the lack of staff training could cause the preparation of large meals, or limited awareness about food waste procedures. However, for a sustainability programme to thrive, top managers should reward individuals who demonstrate their level of commitment to the company's policies (Demen Meier et al. 2015).

\subsubsection{Management strategies}

Sustainability education and training for staff could be used as a mechanism to achieve a comprehensive use of environmental resources. Better training of staff will then become an added value in educating clients to order carefully to avoid leftovers and offering different portion sizes or a doggy bag to clients to take leftovers home (Sustainable Restaurant Association 2010; WRAP 2015), also indicating the most accurate information about the calories for each meal and the portions, in order to be able to prevent possible waste during the consumption phase.

When restaurants have excess food, due to the mistake in forecasting or in the impossibility to predict the number of guests, this can be discounted and sold through the dedicated food rescue apps, such as the Too Good to Go, or via the digital food distribution platforms, such as Deliveroo and/or UberEats (de Almeida Oroski 2020). In particular, To Good To Go is a service aimed at supporting consumers to buy unsold (but still good) food products from coffee bars, restaurants and supermarkets that would otherwise be forced to throw away at the end of the day. For vendors and customers, membership is free and with no obligations, except for a percentage that the app retains from individual transactions (https://toogoodtogo. com).

Similarly, Bring the Food is a startup that allows facilitating the meeting between small food companies that have surpluses to dispose of and entities or organizations that can use them for voluntary organizations such as soup kitchens. Within this platform companies (e.g. supermarket or fruit and vegetable store) publish their food surplus, making it visible to charitable structures. The constraint for the user is to book at least one day in advance for their order, ensuring that the restaurant can better manage the supply of raw materials and limit surpluses, with economic advantage for its business (and for all the actors in the chain, starting with the producer) and to avoid food waste. In 2020, the service allowed the recovery and distribution of more than 3 million servings of food to people in need (https://bringfood.org/).

All these food waste management activities can be supported by consumer awareness campaigns carried out directly by foodservice operators, allowing consumer preferences in the long-term (Filimonau et al. 2020). It is also recommended that those in charge of a catering service properly manage the menu of the dishes they 
will offer. Basing the dishes on the menu on foods that are seasonal and therefore cheaper, is a good option to save money in purchasing raw materials. In addition, keeping the list of dishes served in the same period allows to have a rough idea on what should be the expense forecast.

\subsection{Clients consumption food waste (CFW)}

\subsubsection{Description}

Client Food Waste (CFW) is the food scraps left on client's plates or more precisely "food wasted by customers after being served" (Papargyropoulou et al. 2016, p. 4). One of the main reasons for client leftovers is the large portions served in restaurants (Pinto et al. 2018; Sustainable Restaurant Association 2010; WRAP 2015).

\subsubsection{Actors}

In this phase, chefs need to serve reasonably sized portions that fit the client's needs. This fact is confirmed by a recent study conducted on CFW in the UK, in which $40 \%$ of the clients interviewed stated that the customization of portion sizes, a larger variety of available portion sizes and prices could enable restaurants to reduce food waste and offer clients the possibility of eating smaller portions for a minor cost (WRAP 2015).

At the same time, staff and restaurant managers must be able to suggest the best types of dishes according to the customer's needs, giving as much information as possible about the composition of the dishes and the combinations to suggest (Vercammen et al. 2020).

\subsubsection{Causes}

According to some studies (Jun and Min 2000; Gaiani et al. 2018), a reason that leads people to leave leftovers is the presence of additional food, such as bread, crackers, and breadsticks, which are consumed while waiting for the main dishes. Another factor that leads to the creation of food leftovers, is the lack of description of the information on the calories and quantities shown in the menus, as well as the ingredients contained in the plates (Krieger et al. 2013; Block et al. 2013).

\subsubsection{Management strategies}

Client food waste can be reduced through better portioning standards and awareness programs, such as leftover catering would be considered as the post-consumer waste if it has not been received by an individual customer during the service (Eriksson et al. 2017). Alternatively, restaurants can offer various portion sizes in order to choose the desired size (Betz et al. 2015). Moreover, in some cases restaurants can encourage the consumer to avoid leftovers charging clients by the weight of the food they order, rather than per portion (Kallbekken and Saelen 2013). 
Furthermore, an increase in the adoption of doggy bags could help to reduce this type of food waste (Sustainable Restaurant Association 2010; WRAP 2015). The contemporary doggy bag contains portions of lunch or dinner not consumed, which the customer can comfortably recycle at home. In this way, a restaurant can avoid throwing away huge quantities of cooked food and at the same time, the customer can have a ready-made meal. For both parties, this is a considerable saving and avoids waste. In some European countries and in the USA, doggy bags are widely accepted at all social levels, while in southern European countries are not common practices yet. For example, a recent research in Italy showed that about $90 \%$ of Italians indicate that restaurants waste a large amount of food, $41 \%$ are embarrassed to ask for a doggy bag (Last Minute Market, SWG 2016). Other studies revealed that only $36 \%$ of Italians have taken leftovers home from restaurants at least once, while 22\% think that asking for a doggy bag is a sign of bad manners (Coldiretti 2017; similar results were found by Sirieix et al. 2017). Using these solutions sustainable restaurants can influence diner behavior as a second-order construct of participation in waste reduction practices, and as a result enhance customer loyalty (Kim and Hall 2020).

\section{Discussion}

By carrying out a thematic literature review on food waste at the restaurant level and thus proposing a map called the Restaurant Food Waste Map (RFWM), we gained valuable literature knowledge and insights on a specific stream of research-which has been little considered until now- that is, out-of-home food waste.

RFWM was designed to describe the phases in which the food waste phenomenon occurs, and to identify main activities of food waste generation processes.

The factors that restaurants should take into consideration in the service phase are: (1) the change of menu planning, hold regular training session and the correct indication of the doses and quantities of the ingredients in the dishes; (2) the creation of manuals with well-defined waste management procedures; (3) the offer of doggy bags to clients. These considerations are in line with the results of other studies, according to which technological solutions include the introduction or change of technologies and/or things that look for change the behaviors around food waste (Devaney and Davis 2017; Ganglbauer et al. 2013; Lazell 2016; Lim et al. 2017; Wansink and van Ittersum. 2013; Williamson et al. 2016; Young et al. 2017). These involved changes to plate or portion sizes (Williamson et al. 2016). The major signalized waste reduction (57\%) was due to changing to smaller plate sizes (Wansink and van Ittersum 2013); other studies have reported that, a reduction in plate size, cause a 19\% reduction in food waste (Kallbekken and Sælen 2013). The abundance of portions and the combinations of ingredients that consumers dislike is the most important fraction of the losses in the catering sector (Demen Meier et al. 2015).

Client food surplus can be reduced through: (1) check of the information on the calories and quantities shown in the menus when choosing meals; (2) avoid leftovers by ordering smaller portion sizes; (3) Doggy bag adoption. These approaches are consistent with Reynolds et al. (2019), according to which a solution to prevent and 
reduce clients food waste could be encourage them to order portions that are in line with how hungry they are (Jagau et al. 2017), or to take smaller portions at a buffet and return to take them if you want more (Kallbekken and Sælen 2013). This type of measure, as relatively simple and cheap, could be combined with other measures, such as establishing a lower price for a smaller portion (Reynolds et al. 2019). Concerning the approaches to food waste management, doggy bags are a concrete solution to reduce out-of-home waste. In fact, it has been observed that the people who are more likely to waste more food out-of- home than at home are those who are unaware of the doggy bags used (Principato et al. 2017).

However, sustainability commitment requires a medium-long time to be implemented and to be seen as holistic: restaurants have to pay attention to every point of the culinary chain, from direct farmer relationships to reusing all their organic waste and recycling any non-biodegradable waste that is generated. Covid-19 has thrown long-term plans. The pandemic has had a disproportionate impact on food supplies and food waste (Principato et al. 2020), and in particular in the restaurant industry, due to shutdowns in most of the sector. The expectations generated during the lockdown period regarding the importance of a different model of development based on the principles of social and environmental sustainability that could mature at all levels and seem to be wavering.

Moreover, some individuals' concerns like the food safety and contamination issues surrounding Covid-19 have already compelled many food businesses to revert to single-use plastic packaging. Nevertheless, we believe that zero-waste restaurants may be well-positioned to remain viable. Their sheer cost-effectiveness, along with carefully nurtured supply chains and a committed culture may actually make them more robust in the face of financial stress.

After clarifying the approaches of the food waste phenomenon, our paper proposes valuable suggestions that can significantly reduce food waste at the restaurant level, such as re-use edible food for making other recipes, offering different portion sizes, and creating manuals with well-defined waste management procedures. According to their specific roles, consumers, companies, and institutions should take synergic action. Because restaurants can reduce food waste along their entire supply chain, from supplier to consumer, there is an enormous opportunity. Restaurant food waste can be roughly divided into two major groups: the one that left before consuming food (prevention and reduction) and the one that left after consumers finish dining (reuse) (Cicatiello et al. 2019). For example, a food waste preventive assessment could help restaurants to collect information on how much garbage or leftover food they create and what is the quantity of waste, also in Ho.re.ca. (Arvanitoyannis 2010; Secondi et al. 2019a; Vizzoto et al. 2020), that can be reduced through the practice of waste management, recycling, reuse, and redistribution.

If the restaurant is not able to predict demand forecasting in the best possible way, an over-production of meals is generated, which leads to the majority of food waste (Filimonau et al. 2020). Managers could provide training courses to kitchen staff to make better use of raw materials, and to support the creation of menus with excess food ingredients. Also, chefs could prepare portions that fit customer expectations (Betz et al. 2015) and that better reflect the ways to avoid waste due to aesthetics reasons (Charlebois et al. 2016). 
In the Kitchen Food Waste phase, the factors that restaurants should consider in order to avoid food surplus are: (1) the comparison between food purchase and quantity of garbage and the consideration of the seasonality of food production in relation to the availability of it; (2) the excessive size of the portions of food served and the focus of training staff; (3) the scarce diffusion of the practices that allowed customers to bring home the leftovers or the support on donation activities for surplus food.

To avoid food waste due to expired or spoiled food, restaurants could improve the monitoring of food inventory and stock: the practices of FIFO (First In First Out) and FEFO (First Expired First Out) are suggested practices in controlling the inventory in restaurants since the stock is rotated frequently, and close-to-date stock can be used first before they expire (Ahrens and Chapman 2002a, b). Furthermore, knowing the inventory on a daily basis allows chefs to place suitable menus and have better control of possible spoilage. Finally, restaurants could leverage relationships with food banks to donate leftover food. Food banks are organizations that collect and save the food in warehouses in order to distribute to hungry families and individuals (Schneider 2013). Digital tools could support these issues. According to the recent literature, food sharing models and digital solutions, such as web platforms and food sharing apps, seem to be promising tools for diminishing the food waste phenomenon, and especially food waste produced when eating out, with the main aim of redistributing surplus food with different methods and formulas (see Michelini et al. 2018; Harvey et al. 2020; Secondi et al. 2019a). Recently numerous applications and online platforms have simplified the food donation procedure, helping to improve donation activities (Schneider 2013). Moreover, digitalization and sharing economy makes it possible to find interesting solutions that allow food waste to be prevented and minimized from both business and client perspective (Michelini et al. 2018).

Furthermore, for restaurants it is helpful to have a point person accountable for food waste reduction who can oversee all aspects of waste reduction-prevention, reduction, and recycling - and take responsibility for engaging internal staff, consumers, and external stakeholders. The engagement of consumers is also fundamental. This paper suggests some practical approaches to active customer engagement in the mitigation of restaurant food waste, such as checking the information on the quantities shown in the menus, ordering smaller portion sizes, and adopting doggy bags.

Activities such as giving better information (Manomaivibool et al. 2016) or modification of the type and size of the plate (Lazell 2016; Wansink and van Ittersum 2013; Williamson et al. 2016), portion size, or the structure of the menu (Cohen et al. 2014; Martins et al. 2016; Schwartz et al. 2015), all could contribute to reducing service food waste. A similar solution is described by Secondi et al. (2019a), according to which to reduce leftovers on the plate, restaurateurs could offer a choice of small, medium, and large portions for the same dish at different prices, while the use of food apps, in order to recover any food surpluses, would allow to "re-circulate" still good and uneaten food and, at the same time, could provide an additional profit to the restaurateurs. (Secondi et al. 2019a).

Correct information on how to collect and redistribute surplus food can help strengthen the virtuous mechanism activated by those (hotels, catering companies, 
and event organization agencies) that already choose to allocate the food that remains after a buffet, or lunch to those who cannot afford to buy it. Another very important aspect to be considered in the development of a culture oriented towards the circular economy through training interventions to encourage the development and acquisition of dedicated skills; as well as working on tax relief on circular economy interventions, such as the reduction of VAT on eco-design products, or a tax deduction to be modulated according to the interventions made and the number of companies involved in the food waste recovery (Närvänen et al. 2020).

In line with this, recently, the EU promoted an alternative economic growth based on a cyclical flow process that ensures a more sustainable development, the Circular Economy (CE) model (MacArthur 2015; CIRAIG 2015; Ruggieri et al. 2016). According to this model, food waste can be recycled, reused, and redistributed using a closed-loop perspective, instead of the old linear input-output process and could have a second life by using them as secondary raw materials and energy (Secondi et al. 2019b). Moreover, because some type of food waste is unavoidable, waste management should not only put attention to waste prevention but also considering actions to reuse and/or recycle it to make renewable energy (Valenti et al. 2017).

In fact, recovering and redistributing surplus food for social purposes promotes the transition to a circular economy because it makes collaboration between different actors in the food supply chain more efficient. Innovative business models that apply this strategy to prevent food waste include the recovery and redistribution of surplus food for social purposes (Franceschelli et al. 2018). To date, the best possible destination of food surpluses, which ensures the highest use-value of food resources suitable for consumption, is their redistribution for human consumption. The donation of food not only helps to reduce food poverty but can also become an effective lever to reduce food surpluses that are used for industrial uses or destined for landfill treatment as waste. However, although redistribution of surplus food is a growing phenomenon, and there is a willingness on the part of food producers and retailers to donate surplus food to food banks and charities, redistributed products still represent a modest share of the total edible surplus food available (Tarasuk and Eakin 2005).

The purpose of this set of measures could lead to the development of so-called zero-waste restaurants. A zero-waste restaurant is a restaurant that does not produce any trash or food waste and applies procedures in order to minimize its carbon footprint on the world and embrace a completely eco-friendly ethos (Principato 2018; Hottle et al. 2015; Hyde et al. 2001). The zero-waste model is a growing trend, but in Italy, it is struggling to establish. In this country, in fact, a traditionalist vision of the restaurant still prevails, based on scarce managerial and organizational knowledge, which resists changes and has and has limited understanding of digital (FIPE 2019). The Italian State has tried to take a further step forward for a zero-waste policy with the Gadda Law (166/2016), which, instead of being based on the principle of obligation, provides for bureaucratic simplifications, tax relief, and bonuses to better manage food surpluses. Really putting into practice zero waste work, in a system that encourages and enhances good practices and collaboration between stakeholders.

The Gadda Law, having clarified, harmonized, and simplified the regulatory framework of this issue, provides greater incentive for companies, supermarkets, 
commercial businesses, and restaurateurs to donate excess food, allowing all nonprofit organizations to recover even more food. The law has also widened the range of subjects with a social purpose who can benefit from food to support people in need. Another positive impact of the Gadda law is that makes all stakeholders responsible, involving them in a virtuous process that is good first of all for the companies themselves, avoiding the use of sanctions. The law also introduces the possibility for municipalities to reduce the waste tax for companies that document donation; and has removed the obstacles companies and voluntary associations encountered in the recovery of surplus food, often caused by ignorance or incorrect communication.

\section{Concluding remarks}

This paper proposes a map for investigating food waste in the foodservice sector. The distinction in our RFWM map between food waste generated in kitchens (KFW), during service (SFW), and in clients 'consumption (CFW) enabled us to highlight the factors and characteristics associated with food waste in the restaurant sector. From this standpoint, the exploratory nature of the study may allow us to effectively frame the research question and suggest researchers on conducting further studies on this topic, as well as restaurant managers and policymakers. Furthermore, we emphasize the importance of identifying the stages of food waste production in order to recognize specific factors related to each stage. In particular, an empirical study could be conducted in future research in order to measure how much the implementation of prevention, reduction and reuse practices identified along the stages within the map can support the sustainability commitment of restaurants over time.

With little adjustments, this model could easily fit with other home services settings, like catering service, and hospital/worksite/school canteens. In particular, the service food waste phase is the one that could potentially overlap with kitchen food waste, depending on the type of catering offered in the restaurant/food service. For instance, if the catering is mainly conceived as a counter service, the service phase could easily be removed from the map and be absorbed by the kitchen food waste phase. Similarly, some mitigation strategies can be taken at different levels. Indeed, "change menu in order to minimize the number of leftovers" could be either taken at the kitchen or service level.

The paper has some limitations, especially concerning the scope of analysis of the proposed map. A comprehensive view of the overall restaurant sector is difficult to obtain because it consists of numerous sub-sectors with specific operational and organizational issues that can affect food waste (Christ and Burritt 2017). Furthermore, it is nevertheless important to say that the different influences and incorrect behavior described in the model could not be seen as exhaustive. Yet, researchers are encouraged to fill the map with other factors and influences that impact wasteful behavior. This is due to the fact that some activities on the practical side are difficult to carry out for various reasons, above all the infrastructural limits of restaurants, as well as a lack of basic concern for sustainability throughout the entire sector. 


\section{References}

Ahrens, T., \& Chapman, C. (2002a). The structuration of legitimate performance measures and management: day-to-day contests of accountability in a UK restaurant chain. Management Accounting Research, 13(2), 151-171.

Ahrens, T., \& Chapman, C. (2002b). The structuration of legitimate performance measures and management: Day-to-day contests of accountability in a UK restaurant chain. Management Accounting Research, 13(2), 151-171.

Arancon, R. A. D., Lin, C. S. K., Chan, K. M., Kwan, T. H., \& Luque, R. (2013). Advances on waste valorization: New horizons for a more sustainable society. Energy Science and Engineering, 1(2), 53-71.

Arvanitoyannis, I. S. (2010). Waste management for the food industries. New York: Elsevier.

Betz, A., Buchli, J., Göbel, C., \& Müller, C. (2015). Food waste in the Swiss food service industry-magnitude and potential for reduction. Waste Management, 35, 218-226.

Block, J. P., Condon, S. K., Kleinman, K., Mullen, J., Linakis, S., Rifas-Shiman, S., \& Gillman, M. W. (2013). Consumers' estimation of calorie content at fast food restaurants: Cross sectional observational study. BMJ, 346, f2907.

Champions123 (2019) The business case for reducing food loss and waste restaurants. https://champ ions 123.org/wp-content/uploads/2019/02/Report_The-Business-Case-for-Reducing-Food-Loss-andWaste_Restaurants.pdf. Last access 2020 May 07.

Charlebois, S., Schwab, A., Henn, R., \& Huck, C. W. (2016). Food fraud: An exploratory study for measuring consumer perception towards mislabeled food products and influence on self-authentication intentions. Trends in Food Science and Technology, 50, 211-218.

Chou, C. J., Chen, K. S., \& Wang, Y. Y. (2012). Green practices in the restaurant industry from an innovation adoption perspective: Evidence from Taiwan. International Journal of Hospitality Management, 31(3), 703-711.

Christ, K. L., \& Burritt, R. L. (2017). Water management accounting: A framework for corporate practice. Journal of Cleaner Production, 152, 379-386.

Cicatiello, C., Franco, S., Pancino, B., \& Blasi, E. (2016). The value of food waste: An exploratory study on retailing. Journal of Retailing Consumer Service, 30, 96-104.

Cicatiello, C., Secondi, L., \& Principato, L. (2019). Investigating consumers' perception of discounted suboptimal products at retail stores. Resources, 8(3), 129.

CIRAIG (International Reference Centre for the Life Cycle of Products, Processes and Services). (2015). Circular economy: A Critical literature review of concepts. Montreal, QC: Polytechnique Montréal.

Cohen, J. F., Richardson, S., Parker, E., Catalano, P. J., \& Rimm, E. B. (2014). Impact of the new US Department of Agriculture school meal standards on food selection, consumption, and waste. American Journal of Preventive Medicine, 46(4), 388-394.

Coldiretti (2017). Coldiretti/Censis, home restaurant per $3 \mathrm{mln}$ di italiani, 20 ottobre. http://www.coldi retti.it/economia/coldiretticensis-home-restaurant-3-mln-italiani. 10 Dicembre 2017.

Collison, R., \& Colwill, J. (1985). The analysis of food waste results and related attributes of restaurants and public houses. Foodservice Research International, 4(1), 17-30.

Curtis, K. R., \& Slocum, S. L. (2016). The role of sustainability certification programs in reducing food waste in tourism. Journal of Developments in Sustainable Agriculture, 11(1), 1-7.

de Almeida Oroski, F. (2020). Exploring food waste reducing apps-a business model lens. In: E. Närvänen, N. Mesiranta, M. Mattila, \& A. Heikkinen (Eds.), Food Waste Management. Cham: Palgrave Macmillan. https://doi.org/10.1007/978-3-030-20561-4_14.

Demen Meier, C., Siorak, N., Buri, S., \& Cornuz, C. (2015). Sustainable supply chains and environmental and ethical initiatives in restaurants. In P. Sloan \& W. Legrand (Eds.), The Routledge handbook of sustainable food (pp. 267-278). Routledge.

Devaney, L., \& Davies, A. R. (2017). Disrupting household food consumption through experimental HomeLabs: Outcomes, connections, contexts. Journal of Consumer Culture, 17(3), 823-844.

Di Leo, A., Michelini, L., \& Principato, L. (2019). Food sharing and innovative business modes, cap 20. In M. Kosseva (Ed.), Food industry wastes: Assessment and recuperation of commodities (2nd ed.). London: Elsevier.

Environmental Protection Agency (EPA). (2019). Sustainable management of food: Food recovery hierarchy. Retrieved January 14, 2021, from https://www.epa.gov/sustainable-management-food/foodr ecovery-hierarchy\#about. 
Eriksson, M., Osowski, C. P., Malefors, C., Björkman, J., \& Eriksson, E. (2017). Quantification of food waste in public catering services-A case study from a Swedish municipality. Waste Management, $61,415-422$.

Euromonitor International (2016). Consumer food service. http://www.euromonitor.com/consumerfo odservice. Retrieved June 7, 2020.

Evans, D. M. (2014). Food waste: Home consumption, material culture and everyday life. New York: Bloomsbury Publishing.

Fanfani, R. (2009). The agri-food system in Italy, major changes and recent trends. Bologna: Edagricole.

FAO (2019). The State of Food and Agriculture 2019. Moving forward on food loss and waste reduction. Rome. Licence: CC BY-NC-SA 3.0 IGO.

Filimonau, V., \& Delysia, A. (2019). Food waste management in hospitality operations: A critical review. Tourism Management, 71, 234-245.

Filimonau, V., Matute, J., Kubal-Czerwińska, M., Krzesiwo, K., \& Mika, M. (2020). The determinants of consumer engagement in restaurant food waste mitigation in Poland: An exploratory study. Journal of Cleaner Production, 247, 119105.

FIPE (2019). Rapporto Annuale Ufficio Studi. Disponibile al link https://www.fipe.it/centro-studi/2019. html?download=730:ristorazione-2019.

Franceschelli, M. V., Santoro, G., \& Candelo, E. (2018). Business model innovation for sustainability: A food start-up case study. British Food Journal, 120(10), 2483-2494.

Gaiani, S., Caldeira, S., Adorno, V., Segrè, A., \& Vittuari, M. (2018). Food wasters: Profiling consumers' attitude to waste food in Italy. Waste Management, 72, 17-24.

Ganglbauer, E., Fitzpatrick, G., \& Comber, R. (2013). Negotiating food waste: Using a practice lens to inform design. ACM Transactions on Computer-Human Interaction (TOCHI), 20(2), 1-25.

Gössling, S., Garrod, B., Aall, C., Hille, J., \& Peeters, P. (2011). Food management in tourism: Reducing tourism's carbon “foodprint. Tourism Management, 32(3), 534-543.

Harvey, J., Smith, A., Goulding, J., \& Illodo, I. B. (2020). Food sharing, redistribution, and waste reduction via mobile applications: A social network analysis. Industrial Marketing Management, 88, 437-448.

Heikkilä, L., Reinikainen, A., Katajajuuri, J. M., Silvennoinen, K., \& Hartikainen, H. (2016). Elementsaffecting food waste in the food service sector. Waste Management, 56, 446-453.

Hottle, T. A., Bilec, M. M., Brown, N. R., \& Landis, A. E. (2015). Toward zero waste: Composting and recycling for sustainable venue-based events. Waste Management, 38, 86-94.

Hyde, K., Smith, A., Smith, M., \& Henningsson, S. (2001). The challenge of waste minimization in the food and drink industry: A demonstration project in East Anglia, UK. Journal of Cleaner Production, 9, 57-64.

Jagau, H. L., \& Vyrastekova, J. (2017). Behavioral approach to food waste: An experiment. British Food Journal, 119, 882-894.

Jun, M., \& Min, H. (2000). Study on effective methods for reducing leftovers in the food service businessand industry. Korean Journal of Community Nutrition, 5(1), 92-99.

Kallbekken, S., \& Sælen, H. (2013). 'Nudging' hotel guests to reduce food waste as a win-win environmental measure. Economics Letters, 119(3), 325-327.

Kim, M. J., \& Hall, C. M. (2020). Can sustainable restaurant practices enhance customer loyalty? The roles of value theory and environmental concerns. Journal of Hospitality and Tourism Management, 43, 127-138.

Kreeger, J. C., Parsa, H. G., Smith, S. J., \& Kubickova, M. (2018). Calendar effect and the role of seasonality in consumer comment behavior: A longitudinal study in the restaurant industry. Journal of Foodservice Business Research, 21(3), 342-357.

Krieger, J. W., Chan, N. L., Saelens, B. E., Ta, M. L., Solet, D., \& Fleming, D. W. (2013). Menu labeling regulations and calories purchased at chain restaurants. American Journal of Preventive Medicine, 44(6), 595-604.

Last Minute Market, SWG. (2016). Waste watcher 2016 report. Last Minute Market, Bologna.

Lazell, J. (2016). Consumer food waste behaviour in universities: Sharing as a means of prevention. Journal of Consumer Behaviour, 15(5), 430-439.

LeanPath. (2008). Short guide to food waste management best practices. www.leanpath.com/docs/Waste_ Guide_o.pdf.

Lim, V., Funk, M., Marcenaro, L., Regazzoni, C., \& Rauterberg, M. (2017). Designing for action: An evaluation of Social Recipes in reducing food waste. International Journal of Human-Computer Studies, 100, 18-32. 
MacArthur, E., Zumwinkel, K., \& Stuchtey, M. R. (2015). Growth within: A circular economy vision for a competitive Europe. Isle of Wight: Ellen MacArthur Foundation.

Manomaivibool, P., Chart-asa, C., \& Unroj, P. (2016). Measuring the impacts of a save food campaign to reduce food waste on campus in Thailand. Applied Environmental Research, 38(2), 13-22.

Marthinsen, J., Sundt, P., Kaysen, O., Kirkevaag, K. (2012). Prevention of food waste in restaurants, hotels, canteens and catering. Nordic Council of Ministers, Copenhagen.

Martinez-Sanchez, V., Tonini, D., Møller, F., \& Astrup, T. F. (2016). Life-cycle costing of food waste management in Denmark: Importance of indirect effects. Environmental Science and Technology, 50(8), 4513-4523.

Martin-Rios, C., Demen-Meier, C., Gössling, S., \& Cornuz, C. (2018). Food waste management innovations in the foodservice industry. Waste Management, 79, 196-206.

Martins, M. L., Rodrigues, S. S., Cunha, L. M., \& Rocha, A. (2016). Strategies to reduce plate waste in primary schools-experimental evaluation. Public Health Nutrition, 19(8), 1517-1525.

Michelini, L., Principato, L., \& Iasevoli, G. (2018). Understanding food sharing models to tackle sustainability challenges. Ecological Economics, 145, 205-217.

Mourad, M. (2016). Recycling, recovering and preventing "food waste": Competing solutions for food systems sustainability in the United States and France. Journal of Cleaner Production, 126, 461-477.

Närvänen, E., Mesiranta, N., Mattila, M., \& Heikkinen, A. (2020). Introduction: A framework for managing food waste. In E. Närvänen, N. Mesiranta, M. Mattila, \& A. Heikkinen (Eds.), Food Waste Management. Cham: Palgrave Macmillan. https://doi.org/10.1007/978-3-030-20561-4_1.

Papargyropoulou, E., Lozano, R., Steinberger, J. K., Wright, N., \& bin Ujang, Z. . (2014). The food waste hierarchy as a framework for the management of food surplus and food waste. Journal of Cleaner Production, 76, 106-115.

Papargyropoulou, E., Wright, N., Lozano, R., Steinberger, J., Padfield, R., \& Ujang, Z. (2016). Conceptual framework for the study of food waste generation and prevention in the hospitality sector. Waste Management, 49, 326-336.

Pinto, R. S., dos Santos Pinto, R. M., Melo, F. F. S., Campos, S. S., \& Cordovil, C. M. D. S. (2018). A simple awareness campaign to promote food waste reduction in a University canteen. Waste Management, 76, 28-38.

Pirani, S. I., \& Arafat, H. A. (2016). Reduction of food waste generation in the hospitality industry. Journal of Cleaner Production, 132(20), 129-145.

Principato, L. (2018). Food waste at consumer level: A comprehensive literature review. Berlin: Springer.

Principato, L., Mattia, G., Di Leo, A., \& Pratesi, C. A. (2021). The household wasteful behaviour framework: A systematic review of consumer food waste. Industrial Marketing Management, 93, 641-649.

Principato, L., Pratesi, C. A., \& Secondi, L. (2017). Towards Zero Waste: An Exploratory Study on Restaurant managers. International Journal of Hospitality Management, 74, 130-137.

Principato, L., Secondi, L., Cicatiello, C., \& Mattia, G. (2020). Caring more about food: The unexpected positive effect of the Covid-19 lockdown on household food management and waste. Socio-Economic Planning Sciences, 100953.

Quested, T. E., Marsh, E., Stunell, D., \& Parry, A. D. (2013). Spaghetti soup: The complex world of food waste behaviours. Resources, Conservation and Recycling, 79, 43-51.

Reynolds, C., Goucher, L., Quested, T., Bromley, S., Gillick, S., Wells, V. K., et al. (2019). Consumption-stage food waste reduction interventions-What works and how to design better interventions. Food Policy, 83, 7-27.

Risku-Norja, H., Kurppa, S., Silvennoinen, K., Nuoranne, A., Skinnari, J. (2010). Julkiset ravitsemispalvelut ja ruokakasvatus: arjen käytäntöjen kautta kestävään ruokahuoltoon. MTT. Tampereen yliopistopaino Juvenesprint Oy. pp. 56. Available in Finnish.

Ruggieri, A., Braccini, A. M., Poponi, S., \& Mosconi, E. M. (2016). A meta-model of inter-organizational cooperation for the transition to a circular economy. Sustainability, 8(11), 1153.

Ruiz-Molina, M. E., Gil-Saura, I., \& Berenguer-Contrí, G. (2014). Information and communication technology as a differentiation tool in restaurants. Journal of Foodservice Business Research, $17(5), 410-428$.

Schneider, F. (2013). The evolution of food donation with respect to waste prevention. Waste Management, 33(3), 755-763. 
Schwartz, M. B., Henderson, K. E., Read, M., Danna, N., \& Ickovics, J. R. (2015). New school meal regulations increase fruit consumption and do not increase total plate waste. Childhood Obesity, 11(3), 242-247.

Secondi, L., Principato, L., \& Mattia, G. (2019a). Can digital solutions help in the minimization of outof-home waste? An analysis from the client and business perspective. British Food Journal, 122(5), 1341-1359.

Secondi, L., Principato, L., Ruini, L., \& Guidi, M. (2019b). Reusing food waste in food manufacturing companies: The case of the tomato-sauce supply Chain. Sustainability, 11(7), 2154

Sirieix, L., Lálab, J., \& Kocmanováb, K. (2017). Understanding the antecedents of consumers' attitudes towards doggy bags in restaurants: Concern about food waste, culture, norms and emotions. Journal of Retailing and Consumer Services, 34, 153-158.

Stenmarck, A., Jensen, C., Quested, T., Moates, G. (2016). Reducing food waste through social innovation. Estimates of European food waste levels. ISBN 978-91-88319-01-2.

Sustainable Restaurant Association. (2010). Too Good to Waste.

Tarasuk, V., \& Eakin, J. M. (2005). Food assistance through "surplus" food: Insights from an ethnographic study of food bank work. Agriculture and Human Values, 22(2), 177-186.

Thyberg, K. L., \& Tonjes, D. J. (2016). Drivers of food waste and their implications for sustainable policy development. Resources, Conservation and Recycling, 106, 110-123.

Valenti, F., Porto, S. M. C., Chinnici, G., Cascone, G., \& Arcidiacono, C. (2017). Assessment of citrus pulp availability for biogas production by using a GIS-based model: The case study of an area in southern Italy. Chemical Engineering Transactions, 58, 529-534.

Vandermeersch, T., Alvarenga, R. A. F., Ragaert, P., \& Dewulf, J. (2014). Environmental sustainability assessment of food waste valorization options. Resources, Conservation and Recycling, 87, 57-64.

Venkat, K. (2011). The climate change and economic impacts of food waste in the United States. International Journal on Food System Dynamics, 2(4), 431-446.

Vercammen, K. A., Frelier, J. M., Moran, A. J., Dunn, C. G., Musicus, A. A., Wolfson, J., et al. (2020). Understanding price incentives to upsize combination meals at large US fast-food restaurants. $P u b$ lic Health Nutrition, 23(2), 348-355.

Vizzoto, F., Tessitore, S., Iraldo, F., \& Testa, F. (2020). Passively concerned: Ho.re.ca. managers' recognition of the importance of food waste hardly leads to the adoption of more strategies to reduce it. Waste Management, 107, 266-275.

Wansink, B., \& Van Ittersum, K. (2013). Portion size me: Plate-size induced consumption norms and win-win solutions for reducing food intake and waste. Journal of Experimental Psychology: Applied, 19(4), 320.

Williamson, S., Block, L. G., \& Keller, P. A. (2016). Of waste and waists: The effect of plate material on food consumption and waste. Journal of the Association for Consumer Research, 1(1), 147-160.

WRAP (2015). Strategies to Achieve Economic and Environmental Gains by Reducing Food Waste.

Young, W., Russell, S. V., Robinson, C. A., \& Barkemeyer, R. (2017). Can social media be a tool for reducing consumers' food waste? A behaviour change experiment by a UK retailer. Resources, Conservation and Recycling, 117, 195-203.

\title{
Authors and Affiliations
}

\section{Ludovica Principato ${ }^{1}$ - Alessio Di Leo ${ }^{2}$ (D) . Giovanni Mattia ${ }^{1}$. Carlo Alberto Pratesi ${ }^{1}$}

Ludovica Principato

ludovica.principato@uniroma3.it

\author{
Alessio Di Leo \\ alessio.dileo@uniroma1.it \\ Giovanni Mattia \\ giovanni.mattia@uniroma3.it
}


Carlo Alberto Pratesi

carloalberto.pratesi@uniroma3.it

1 Roma Tre University, Rome, Italy

2 Sapienza University of Rome, Rome, Italy 